\title{
La política migratoria de Trump y el acuerdo México-Estados Unidos: ¿Suficientes para el resguardo de la dignidad migratoria?
}

Daniel Stefano Salazar Urbina ${ }^{1}$

\section{Aporte de Estudiante}

Resumen: Desde épocas anteriores, México y Estados Unidos se sumergieron en un enfrentamiento que comprendió una variedad de causas. Ejemplos de esta afirmación lo constituyen políticas comerciales, de seguridad, migratorias, entre otras. Precisamente, uno de los aspectos que acentuó las rencillas entre los países mencionados, durante los últimos años, ha sido la disyuntiva relativa a los intentos de uniformizar las reglas para establecer un procedimiento migratorio seguro, transparente, no diferenciador y garante de los derechos humanos inherentes a todo migrante centroamericano. Al margen de que se suscribió un acuerdo migratorio entre México y Estados Unidos (la Declaración Conjunta) con el propósito de coadyuvar a aliviar el dilema anterior, no debe olvidarse que tal instrumento fue la respuesta a una rígida política migratoria dirigida por Donald Trump que afectó gravemente lo que se conoce como la dignidad migratoria de los individuos centroamericanos (propiedad humana que desprende el respeto e igual consideración que debe propenderse en favor de los migrantes para con el resto de la sociedad). De esta forma, el objetivo del presente trabajo es determinar la forma en que la irrestricta política migratoria norteamericana degradó la dignidad migratoria, a fin de comprobar si la estructuración de la Declaración Conjunta entre México y Estados Unidos constituyó una herramienta suficiente e idónea para aliviar los problemas que afectaban el tránsito migratorio centroamericano y, sobretodo, la dignidad migratoria.

\section{Influencia de la política migratoria de Trump en la vulneración de la dignidad} migratoria

Desde el ingreso de Donald Trump al gobierno estadounidense, se estructuró una política migratoria que calificaba a la migración ilegal como una amenaza para el crecimiento institucional, social y político, de Estados Unidos (la criminalizaba, en términos sencillos). Se justificó tal postura en un incremento desmesurado de ingresos ilegítimos de migrantes -

\footnotetext{
1 Estudiante del programa de Especialización en Derecho, Gestión y Justicia Electoral organizado el Jurado Nacional de Elecciones (JNE) y en Asociaciones Público Privadas y Proyectos en Activos organizado por Proinversión. Miembro voluntario de la comisión de investigaciones de la asociación civil "lus Inter Gentes" de la Pontificia Universidad Católica del Perú. Asociado del Círculo Internacional Universitario (CIU).

Correo electrónico: danistefasalabina@gmail.com
} 
desde el 2015- los cuales se dedicaban a la comisión de asesinatos u otros delitos en detrimento de miles de ciudadanos estadounidenses (Carrasco, 2017; Loewe, 2018).

La desproporcionada política de Trump se esquematizó de la siguiente manera: (i) se ajustaron las leyes migratorias con el objeto de que todos los migrantes indocumentados sean deportables, (ii) las personas aprehendidas por vulnerar las leyes migratorias debían permanecer en prisión en tanto se finiquitaba su proceso de deportación, (iii) se intensificaron los operativos y arrestos en comunidades que acogían migrantes y (iv) se suprimió el programa DACA (Acción Diferida para los Llegados en la Infancia) a fin de suprimir la protección concedida a los indocumentados que ingresaron a territorio norteamericano cuando eran menores de edad (Armendares y Moreno-Brid, 2019, pp.15-17).

Sobre el particular, consideramos que tales medidas vulneraban la aspiración de salvaguardar la plena vigencia y respeto de la dignidad inherente al migrante. Esta tesis se fundamenta en tres motivos.

En primer lugar, la reestructuración de la normativa que viabilizaba la deportación de cualquier migrante indocumentado constituía un hecho arbitrario al criminalizar a la totalidad de migrantes ilegítimos, y colocaba en una situación de vulnerabilidad a millones de personas que laboraron arduamente para mantener a sus familias desde los inicios de su estadía en Estados Unidos.

En segundo lugar, amenazar con deportar a personas sobre las cuales no subyace indicios de atentar contra las leyes migratorias, y eliminar programas especiales que impedían la deportación de migrantes documentados, no encontraba sustento técnico alguno (y mucho menos, en la seguridad nacional y pública como lo alegó el gobierno norteamericano).

En tercer lugar, las medidas dispuestas por el gobierno de Trump impactaron en términos económicos, sociales y emocionales, en el caso de los migrantes documentados, su temor se basó en la necesidad de tener un encuentro con la autoridad policial que los impulse a no salir de su hogar, salvo para lo estrictamente indispensable; en el caso de los indocumentados, en tanto, ellos temían que se utilice la información personal o laboral para identificar y detener a sus familiares (Armendares y Moreno-Brid, 2019).

Por todo lo expuesto, puede inferirse que el panorama denotado por las políticas migratorias de Trump dañó la dignidad del migrante en gran medida, debido a que ellas impedían su ingreso a los límites estadounidenses por su sola condición de indocumentados y sin atender a criterios proporcionales para denegar sus solicitudes de asilo.

\section{El acuerdo migratorio México-Estados Unidos y su incidencia en el resguardo}

pág. 166 


\section{de la dignidad migratoria}

El acuerdo migratorio (la Declaración Conjunta México-Estados Unidos) costó de dos versiones con características particulares. El primer modelo convenio se concentró en dos aspectos: (i) fundamentos de su firma (las autoridades gubernamentales de México y Estados Unidos estructuraron a la necesidad de garantizar un control de estabilidad de los movimientos migratorios, impedir conductas de discriminación y motivaciones humanitarias, como fundamentos del instrumento) y (ii) reglas para la evaluación de las solicitudes de asilo (todo migrante centroamericano permanecerá en territorio mexicano a la espera del respectivo trámite de asilo, México facilitaría cobijo y trabajo temporal a los migrantes en espera de la respuesta de su solicitud, México no será calificado como Tercer País Seguro, y todo intento de ingreso ilegítimo implicaría la prohibición definitiva de solicitar un nuevo trámite de asilo) (Ortega, 2019, pp.749-750).

No obstante, fue factible advertir que este acuerdo presentó una serie de problemáticas: (i) ausencia de celeridad en el trámite del asilo; (ii) la subjetiva calificación de cada caso como de necesidad humanitaria, (iii) la discordancia entre lo estipulado y lo aplicado en la realidad sobre la asunción del rol de Tercer País Seguro por México, (iv) incremento de índices de ingresos migratorios ilegítimos a territorio americano y $(\mathrm{v})$ desatención del protocolo de espera en México por los retardos en el procesamiento de las solicitudes de asilo (Salazar, 2019, pp. 3-4; Ortega, 2020, pp. 33-34)

Como resultado de ello, se procedió a la revisión del instrumento a mediados del 2019. El fruto de tal análisis culminó con la emisión de una segunda versión del acuerdo migratorio. Entre sus principales disposiciones destacamos el compromiso relativo a ratificar las obligaciones contenidas en el primer acuerdo, así como la esquematización de nuevas medidas: (i) remisión de 6000 agentes de la Guarda Nacional Mexicana a la frontera con Guatemala para combatir los ingresos a territorio norteamericano incumpliendo el procedimiento regular del asilo, (ii) combate al tráfico de migrantes ilegítimos mediante el estancamiento de la operatividad de las cuentas bancarias de los traficantes, y (iii) compromiso de la Unión Americana sobre tramitar, con mayor celeridad, las solicitudes de asilo (Zamora, 2019, p. 2).

Si bien la evaluación y ratificación del acuerdo era fundamental para conservar una política alineada con objetivos estratégicos en provecho de todo migrante, lo cuestionable fue que su implementación se retardó -innecesariamente- a raíz de una confrontación arancelaria entre México y Estados Unidos. La esencia de este enfrentamiento respondió a la imposición norteamericana de un arancel del 5\% a las importaciones mexicanas, advirtiéndose su incremento gradual en tanto no se visualice una considerable reducción del cómputo de ingresos migratorios ilegítimos. Esto porque Estados Unidos culpaba a México 
por crítica situación migratoria afrontada con anterioridad a la firma del segundo convenio (Zamora, 2019, pp. 2-3).

A pesar que lo ideal era visualizar una articulación de esfuerzos entre ambos actores gubernamentales para solucionar a la brevedad posible los dilemas que envolvían al primer acuerdo, lo cierto es que los mismos se concentraron en una disputa infructífera que influyó en un retardo injustificado para la concesión de una solución célere y eficiente a la compleja situación migratoria.

En síntesis, si bien la Declaración Conjunta México-Estados Unidos abarcó propuestas interesantes para la estabilización del clima migratorio en Centroamérica, la presencia de irregularidades alrededor de su ámbito de aplicación (la subjetividad en calificar como atendible los pedidos de asilo, la discrepancia sobre la asunción del rol de Tercer País Seguro, la confrontación arancelaria, etc.), permite aseverar que tal herramienta se constituyó como un avance correcto pero aún insuficiente para resolver los problemas vinculados con el menoscabo a la dignidad del migrante centroamericano.

\section{Reflexión final}

La conexión entre la dignidad y la migración ha sido, es y será un tema de amplia connotación y vigencia en la totalidad del continente americano. Si bien el enfoque planteado en este trabajo partió del análisis de la política migratoria de Donald Trump y la firma de la Declaración Conjunta México-Estados Unidos, ello no enerva que las ópticas de otras investigaciones se orienten a evaluar el fenómeno dignidad y migración a partir de otras perspectivas (por ejemplo, la gobernanza global como mecanismo para la solución del dilema identificado). Independientemente del planteamiento, método y/o técnica que se emplee, la premisa de fondo para los estudios futuros sobre la interacción entre dignidad y migración debe partir del siguiente argumento: el respeto y consideración entre los migrantes, las autoridades gubernamentales y el resto de la sociedad civil, sobre la base de no propender un trato discriminatorio, apostando al fomento de una consideración igualitaria como fundamento de la puesta en práctica de los derechos fundamentales, y respetando las costumbres, la cultura y las opiniones de los migrantes. Aspectos caves que conforman la dignidad migratoria. 


\section{Referencias}

Armendares, P. y Moreno-Brid, J. (2019). La política migratoria de Trump: antecedentes y consecuencias para los migrantes mexicanos y sus comunidades. México y la Cuenca del Pacífico, 8(22), 9-31.

Carrasco, G. (2017). La política migratoria de Donald Trump. Alegatos, (95), 171-198.

Loewe, D. (2018). Dignidad humana y movimientos migratorios. En S. Pérez y C. Trueba (Eds.), Dignidad. Perspectivas y aportaciones de la filosofía moral y la filosofía política (349-373). Anthropos,

Ortega, R. (2019). Seguridad, Migración y Comercio en las relaciones México-Estados Unidos durante la presidencia de Donald Trump. Foro Internacional, 59(3-4), 733-762.

Ortega, E. (2020). ¿México como tercer país (in)seguro? El asilo como derecho humano en disputa. Instituto de Investigaciones Jurídicas de la UNAM.

Salazar, D. (2019). Análisis de la suficiencia del resguardo mexicano para la protección migratoria. WorksBepress. https://works.bepress.com/danielstefanosalazarurbina/8/

Zamora, I. (2019). Aranceles y conflictos políticos en la relación México-Estados Unidos. Cuaderno de Investigación, (57), 2-5. 